\title{
Madden Julian Oscillations in Total Column Ozone, Air Temperature and Surface Pressure Measured over Cochin during Summer Monsoon 2015
}

\author{
Vazhathottathil Madhu \\ Department of Atmospheric Sciences, School of Marine Sciences, Cochin University of Science and Technology, \\ Cochin, India \\ Email: madhuv68@gmail.com
}

Received 15 January 2016; accepted 5 February 2016; published 18 April 2016

Copyright @ 2016 by author and Scientific Research Publishing Inc.

This work is licensed under the Creative Commons Attribution International License (CC BY). http://creativecommons.org/licenses/by/4.0/ c) (i) Open Access

\section{Abstract}

The intra-seasonal variability plays a major role in the inter-annual variability of weather parameters such as rainfall, temperature and pressure which lead to extreme weather events in certain years. The active (more rainy days) and break (less rainy days) periods of Indian summer monsoon heavily depend on the intra-seasonal variability of weather parameters such as wind, pressure and temperature oscillations during the monsoon season. In the present analysis daily total column ozone, surface temperature and surface pressure measured over Cochin using Microtop II Ozonometer (sun Photometer) were used to study the Intra-Seasonal Variations (ISV) of the above parameters during the monsoon season, 2015. The dominant and significant intraseasonal oscillations (ISOs) were identified using an advanced statistical method called the Discrete Mayer's Wavelet (DMW) analysis. Two major ISOs such as Madden Julian Oscillations (MJO, 30 - 60 days) and quasi-bi weekly (12 - 16 days) oscillations were found in TCO, surface temperature and pressure. In TCO an additional mode of ISO with quasi tri-weekly periodicity was also found (16 - 22 day). It is observed that MJO mode is the dominant among all other modes and its positive and negative phases correlate with positive and negative anomalies of the above parameters. The ISO mode in the surface pressure shows an out of phase relation with the Indian summer monsoon rainfall which indicates the active and break periods of Indian summer monsoon. The contribution of MJO mode is dominant in the tropical atmosphere, which modulates the intra-seasonal variability. It is found that for the year 2015 total column ozone, surface pressure and surface temperature show an annual range of $30 \mathrm{DU}, 4 \mathrm{hPa}$ and $1^{\circ} \mathrm{C}$, respectively.

\section{Keywords}

Intra-Seasonal Oscillations, Total Column Ozone (TCO), Madden Julian Oscillation, 


\section{Wavelet Analysis}

\section{Introduction}

The Madden-Julian Oscillation (MJO) is the dominant mode of tropical intra-seasonal variability in the Asiatic monsoon region. The MJO is an eastward moving disturbance of clouds, rainfall, winds, and pressure that traverses the planet in the tropics and returns to its initial starting point in 30 to 60 days, on average. It connects weather and climate and influences high-impact events around the globe including monsoons, tropical cyclones, tornados, cold surges, flood and wildfires. Basic research in modeling, analysis and real time monitoring of MJO will lead to the improvement of intra-seasonal prediction of probabilities of extreme events like drought and floods. The Madden Julian Oscillation (MJO) represents the connection between the weather and seasonal-tointerannual climate variations. It significantly affects the tropical weather, climate and global atmospheric circulations. Many studies have demonstrated that MJO modulates the characteristics and strength of higherfrequency tropical variability, including tropical cyclogenesis and extreme precipitation events. The important timescales of different intraseasonal variations have been identified in the past three decades as the 10 - 20 and the 30 - 50 day scales, in addition to the synoptic scales [1]-[5]. Previous studies suggest that the intraseasonal and interannual variabilities are governed by a common spatial mode of variability [6]-[9]. Indian summer monsoon, which is a part of the Asian monsoon system, exhibits a wide spectrum of variability on daily, subseasonal, interannual, decadal and centennial time scales. The dominant time scales of intraseasonal variations of monsoon circulations and convections are 10 - 20 days and 30 - 60 days with comparable contributions to the total intraseasonal variability in the Indian region [9]. The Madden \& Julian [10] 30 - 50-day mode is believed to be associated with northward propagation of clouds, rainfall and winds from the equatorial Indian ocean [11], whereas the 10 - 20-day mode is believed to be associated with westward propagation clouds, rainfall and winds from the west Pacific. During the summer monsoon season (June to September), a substantial component of this variability of convection and rainfall over the Indian region arises from the fluctuations on the intraseasonal scale between active spells with good rainfall and weak spells or breaks with little rainfall [12]. The interannual variability of the sub-seasonal fluctuations during the monsoon season is large and long intense breaks have an impact on the seasonal monsoon rainfall over the country [13]. It is recognized that intraseasonal variation can have an impact on the seasonal total rainfall of Indian monsoon. Madden and Julian named it the "40 - 50-day oscillation” because of its preferred time scale [14]-[16]. There can be multiple MJO events within a season, and so the MJO is best described as intraseasonal tropical climate variability. Since then it has been called the "30 60-day oscillation" and the "intraseasonal oscillation", but the term "MJO" has now emerged as a favorite in the global climate change scenario. A comprehensive review of Madden Julian Oscillation can be found elsewhere [16]. Earlier there was no universally accepted definition for MJO. The Real-time Multivariate MJO index (RMM) of Wheeler and Hendon is now accepted as the standard definition for MJO [17]. The MJO cycle, as defined by the RMM index, is split up into 8 phases, for convenience. Each phase corresponds to 1/8th of the full cycle. An individual MJO event can last anywhere between 30 and 60 days.

The tropical ozone concentrations are very much linked with the dynamical process of the tropical atmosphere rather than the chemical processes. Tropical weather systems are under the influence of the intraseasonal variability. All the weather systems are modulated by the intra-seasonal variability over this region. However, the impact of the MJO on atmospheric composition, such as ozone $\left(\mathrm{O}_{3}\right)$, has yet to be well documented. The satellite observed tropical total column ozone and their connection to the MJO reveals that intra-seasonal variations (ISV) of the tropical total ozone are large $(\sim \pm 10 \mathrm{DU})$ and comparable to the total ozone variations in annual and interannual time scales associated with the annual cycles, quasi-biennial oscillation, El Niño-Southern Oscillation, and solar cycle [18]. The total ozone anomalies over Pacific Ocean and eastern hemisphere in the subtropics keep a systematic relationship to the MJO convection and dynamics [18]. The study revealed significant influence of MJO on the active and break phases of Indian monsoon. The peak phase of break spells is generally observed during the MJO phases 1 and 2 (when the MJO phase is active over Africa/western parts of India). Madden Julian Oscillation also modulates the amplitudes and activities in equatorial waves and monsoon depressions [19]. MJO can modulate the timing and strength of monsoons [20] [21], and result in jet stream changes that can lead to cold air outbreaks, extreme heat events, and influence tropical cyclone numbers and its strength in nearly 
all ocean basins [22]. Very few studies are available to understand the intra-seasonal variability of tropical column ozone. Studies have demonstrated that Madden-Julian Oscillation (MJO) can modulate storms and tropical cyclones over Indian Ocean and western Pacific [23]. Similar mechanism is responsible for clustering of tropical cyclones and hurricanes in Gulf of Mexico [24], eastern Pacific and western Pacific [25]. The study of intraseasonal variability is very important in the context of climate change and global warming which leads to extreme weather events such as flash floods, and extreme drought, over the tropics around the globe. For the last few years, sunburn cases were reported frequently from different pockets of this study location indicating the ozone depletion and penetration of more UV-B radiation at the surface. Hence we do require more studies of this kind for the proper understanding and predictions of regional weather and climate. Tropical intra-seasonal variability plays a great role in the weather and climate over the tropics. The proper understanding and forecasting of these intra-seasonal oscillations (ISOs) of tropical atmosphere will benefit people living in the tropical regions, and also over the rest of the Earth due to remote "tele-connections" between the weather in the tropics and the weather elsewhere around the globes. In this study, an attempt has been made to understand the seasonal and intraseasonal variability of tropical column ozone, surface pressure and temperature over Cochin during the summer monsoon, 2015.

\section{Materials and Methods}

The daily values of total column ozone, surface temperature and pressure were measured over Cochin using Microtop II Ozonometer during the year January to December 2015. Dobson and Brewer Spectrometers are ground based universally accepted instruments for total column ozone measurements. They give accurate values of total column ozone with an uncertainty of only 2\% [26]. Microtops II instrument is compact, cheaper and portable in nature, which measure TCO accurately in par with these spectrometers. Present study is based on the primary data using the in situ measurements of TCO, temperature and pressure over Cochin and this study is first of its kind from the southern part of India.

\subsection{About the Microtop II Ozonometer}

Total column ozone is measured by recording the differential absorption of solar light intensity in the UV band. The Microtops II Ozonometer (a sun targeted photometer) measure the direct solar radiation in five channels using a collimator with $2.5^{\circ}$ field of view. For each channel a photodiode and narrow band interference filters for the three UV wavelengths $305.5 \mathrm{~nm}, 312.5 \mathrm{~nm}$ and $320.0 \mathrm{~nm}$ are dedicated for the total column ozone measurements. The near infrared bands centered at $940 \mathrm{~nm}$ and $1020 \mathrm{~nm}$ are used to retrieve the water vapor and aerosol optical depth. The Microtops II measures the optical block temperature and it also incorporates a solid state pressure sensor to provide the surface pressure for each measurements. The physical and operational methods of Microtops II instruments were found elsewhere [27] [28]. The performance of Microtops II is validated using the Brewer spectrometer, which is considered as the standard instrument for measuring total column ozone. Brewer Spectrometer points towards sun and measure radiance at six wavelengths viz 303.2, 306.3, 310.1, 313.5, 316.8 and $320.1 \mathrm{~nm}$. The FOV is approximately $3^{\circ}$ and spectral resolution is $0.6 \mathrm{~nm}$. Measurements are carried out manually by pointing the instrument against the sun with the help of light indicator which reflects the sun position in the sun targeted window.

The ozone measurement using Microtops II ozonometer is based on the assumption that intensity of radiation measured at each channel obeys Lambert-Beer Law, which when applied to ozone absorption and Rayleigh scattering by the atmosphere gives intensity as

$$
I=I_{o} \mathrm{e}^{-a \mu \Omega-m \beta P / P_{o}}
$$

$I_{o}$ is the intensity of light of a particular wavelength before it passes through the atmosphere, $I$, the intensity remaining after all processes attenuating the incident radiation have occurred, $\alpha$ is the ozone absorption coefficient at that specific wavelength, $\Omega$ is the amount of ozone, $\mu$ the ratio of the actual and vertical path lengths of the radiation through the ozone layer, $P$ is the pressure of the atmosphere in hPa, $m$ is a quantity known as the air mass, $P_{o}$ is the standard pressure (1013.25 mbar). For $m<2$ the parameters $\mu$ and $m$ are virtually identical. The Microtops II uses the combination of three wavelengths for calculation of the TCO. The channel I ( $\mathrm{Ch}_{12 \mathrm{TCO}}$ - combination of wavelengths $305.5 \mathrm{~nm}$ and $\left.312.5 \mathrm{~nm}\right)$, Channel $\mathrm{II}\left(\mathrm{Ch}_{23 \mathrm{TCO}}\right.$ - combination of $312.5 \mathrm{~nm}$ and $320.0 \mathrm{~nm})$ and Chanel III $\left(\mathrm{Ch}_{123 т \mathrm{TCO}}\right.$ - combination of $305.5 \mathrm{~nm}, 312.5 \mathrm{~nm}$ and $\left.320.0 \mathrm{~nm}\right) \mathrm{cal}-$ 
culate TCO based on the Equation (2), where $\alpha_{12}$ and $\alpha_{23}$ are difference between the ozone absorption coefficients for the corresponding filters.

$$
\mathrm{Ch}_{123 \mathrm{TCO}}=\left(\mathrm{Ch}_{12 \mathrm{TCO}} \cdot \alpha_{12}-\mathrm{Ch}_{23 \mathrm{TCO}} \cdot \alpha_{23}\right) /\left(\alpha_{12}-\alpha_{23}\right)
$$

\subsection{Method of Analysis}

The measurements of TCO, surface temperature, and pressure taken at 11.30 hrs and 14.30 hrs were averaged to get the daily values. Monthly means are calculated using the daily means to study the seasonal variability. The data gaps were filled using the linear interpolation technique. The tropical monsoon rainfall and the monsoon regions are undergoing a lot of intra-seasonal variability with different time scales which can alter the weather and climate, which in turn produce extreme weather events frequently. Considering the above facts, efforts are taken in this work to understand the different time scales of ISOs which play significant role in the total intraseasonal variability. The daily total column ozone, surface temperature and pressure were taken for the period 01 June-30th September, 2015 to study the ISV.

\subsection{Wavelet Analysis}

Wavelet Transform converts a signal into a series of wavelets, which provide a way for analyzing waveforms, bounded in both frequency and time domain. It allows signals to be stored more efficiently than Fourier transform and is very well-suited for approximating data with sharp discontinuities. Wavelet transform can be used effectively to extract the hidden frequency based information from the raw signal which is normally present in the time-domain. Basically the frequency components (spectral components) of the signal show what frequencies exist in the signal. Fourier Transform can tell how much of each frequency exists in a signal and it cannot provide what frequency exists at what time intervals. Wavelet transform can overcome this issue and hence it is widely used for climate data analysis. In the wavelet analysis raw signal (time-domain) decomposes into different frequency components. A Discrete Wavelet Transform (DWT) provides sufficient information both for analysis and synthesis to reduce the computation time sufficiently. It is easier to implement and analyze the signal at different frequency bands with different resolutions. Discrete wavelet transform decompose the signal into a coarse approximation but with detailed information. There are different families of wavelets with different properties suitable for different applications. In this study Mayer's discrete wavelet analysis is used which is not a crude method and have many advantages over other wavelet transform methods. To study the low and high frequency oscillations (ISOs) during the monsoon season, an advance statistical method called Discreet Mayer's Wavelet (DMW) is used. Mathematical steps, algorithms and software packages are available for the easy use of this technique for the climate data analysis [29].

\section{Results and Discussions}

The Microtops II measurements of TCO, surface temperature and pressure measured over the tropical station Cochin were used to understand the seasonal variability and intra-seasonal variability for the year 2015. From the previous studies and literature it is well known that dominant time scales of intraseasonal variation affect monsoon rainfall, cloud, wind, distribution of atmospheric trace gases, such as ozone, water vapor and other weather parameters [9]. Hence the study focuses on the intra-seasonal variability of total column ozone, surface temperature and pressure during the monsoon season (June-September).

\subsection{Seasonal Variation}

To study the seasonal variation of TCO, surface temperature and pressure, daily in situ observations were taken using the hand held Microtop II Ozonometer. Many extreme weather events (increase in frequency of tropical cyclones with hurricane speeds, drought and flood situations) and climate variability has happened across globe in the year 2015. India witnessed the extremes in the weather due to tele-connections of strong El Niño events at the pacific and associated weather changes in the rainfall amount during 2015.

The present work mainly concentrated on the seasonal and intraseasonal study of total column ozone (TCO) measured over Cochin with other weather parameters such as daily surface temperature and pressure at $11.30 \mathrm{hrs}$ and 14.30 hrs. Figures 1(a)-(c), represent the daily mean of monthly values subtracted from the annual mean 


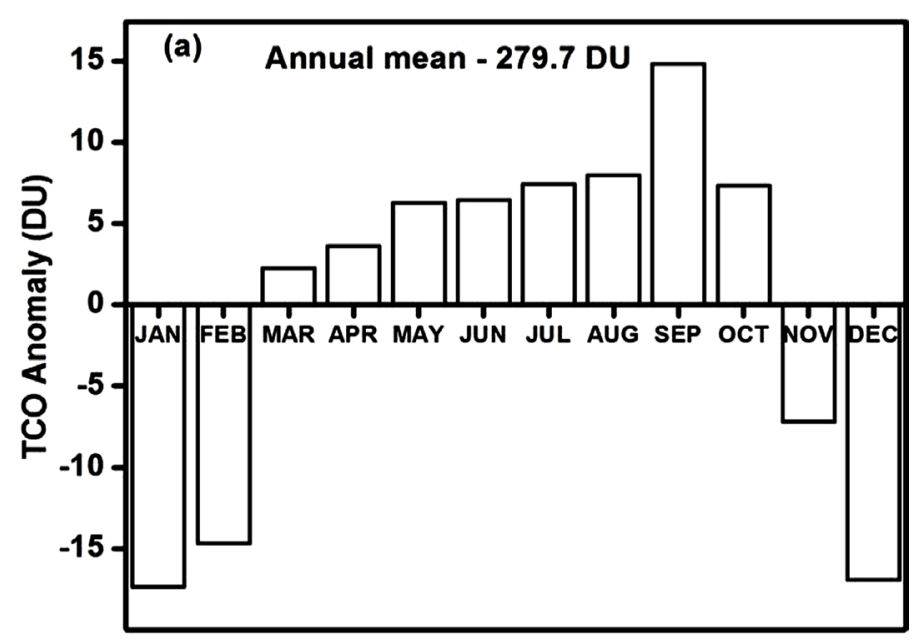

Months (2015)
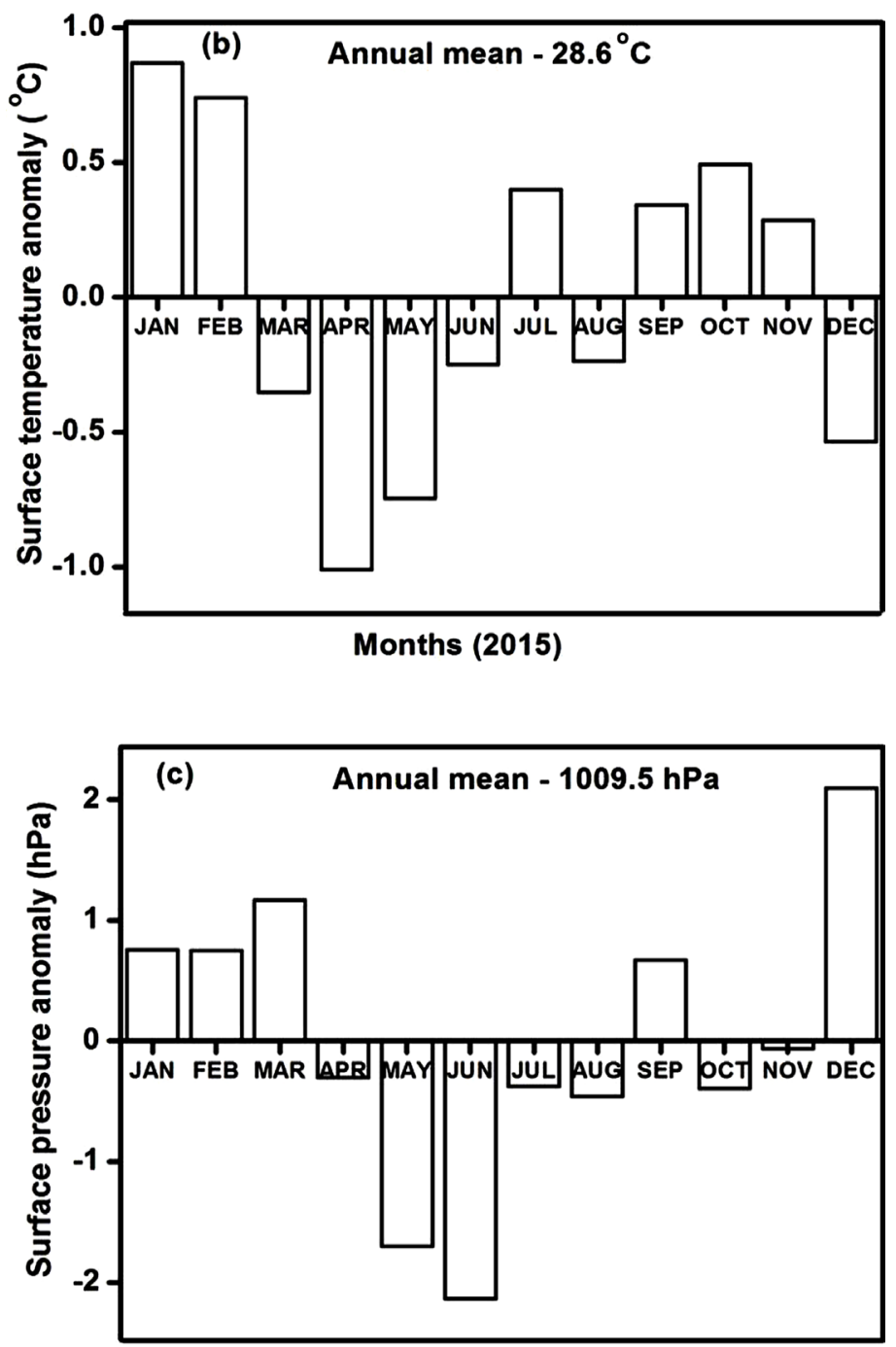

Months (2015)

Figure 1. (a)-(c) represent monthly anomalies of TCO, surface temperature and pressure during the year 2015. 
(279.7 DU) of TCO, surface temperature $\left(28.6^{\circ} \mathrm{C}\right)$ and pressure $(1009.5 \mathrm{hPa})$ respectively. Significant seasonal variations are noted in the above parameters for the year 2015. Maximum variations in the negative TCO anomaly are noted in the months November to February with a peak (-17 DU) in January 2015. From March to September there observed a steady increase in the Total column ozone anomaly and reached a peak value of +15 DU in September. From October onwards there was sudden decline in TCO anomaly to -15 DU within a gap of two months (October-November) from the annual mean. From earlier studies it is observed that total ozone variability is high over tropical Indian monsoon region especially the stations close to the proximity of equator [30]. The above results are true when compared with the 35 year climatology of ECMWF reanalysis of TCO [36].

Interannual variability of TCO is different due to intra-seasonal variability (ISV) of the respective years. During monsoon season (June-September) TCO shows a little higher value from the annual average (279.7 DU) with an increase of $\sim 9 \mathrm{DU}$, which is quite relevant when the tropical ozone variability is concerned. The pre monsoon season (March-May) shows a little lower value (283.7 DU) than the annual average and post monsoon season (October-December) shows still lower value of 274.4 DU (difference of 14 DU from the monsoonal average and $\sim 5$ DU from the annual average). During March-April months, ozone anomaly show very less values ( $>5 \mathrm{DU}$ ) which indicates the thinning of ozone layer and this may lead to more UVB radiation reaching the earth surface over the study location. In the last few years, a number of sunburn cases have been reported over this region and hence this sort of study is quite important when we consider the regional importance of Cochin. From the Figure 1 it is quite evident that TCO varies about 30 DU from January to December period of the year 2015. Even though this value of TCO variation is less compared to that in the high and polar latitudes, this change in value is quite relevant considering the tropical weather and climate.

Figure 1(b) \& Figure 1(c), represents the seasonal variations of surface temperature and pressure over Cochin for the year 2015. The annual and seasonal average of surface temperature and pressure are calculated using the daily values measured by Microtops II. Two observations were made daily at $11.30 \mathrm{hrs}$ and $14.30 \mathrm{hrs}$ and the average value of these two observations are taken as daily value of TCO, Temperature and pressure. The monthly surface temperature fluctuate between $-1^{\circ} \mathrm{C}$ and $+1^{\circ} \mathrm{C}$ from the annual average $\left(28.6^{\circ} \mathrm{C}\right)$ with difference of $1.8^{\circ} \mathrm{C}$ from maximum to minimum during 2015 . That is temperature change is about $2^{\circ} \mathrm{C}$ only throughout the year. In monsoon and post monsoon seasons surface temperature varies in a similar fashion which is almost equal to the annual average $\left(28.6^{\circ} \mathrm{C}\right)$. Pre monsoon shows a little lesser value of surface temperature $\left(27.8^{\circ} \mathrm{C}\right)$ with a difference of $\sim 0.8^{\circ} \mathrm{C}$ from the annual average. During monsoon period surface temperature fluctuates between $-0.3^{\circ} \mathrm{C}$ and $+0.3^{\circ} \mathrm{C}$ and for other seasons, it is greater than $0.3^{\circ} \mathrm{C}$ from the annual mean. Another interesting observation is that temperature fluctuates between negative and positive anomaly in the alternate months during summer monsoon period June to September.

Figure 1(c) shows the monthly surface pressure anomaly over Cochin. Surface pressure oscillates between -2 $\mathrm{hPa}$ and $+2 \mathrm{hPa}$ from the annual mean $(1009.5 \mathrm{hPa})$ for the entire seasons of 2015. The highest surface pressure anomaly is recorded in December ( $\sim+2 \mathrm{hPa}$ ) and the lowest in June ( $-2 \mathrm{hPa})$. The surface pressure over Cochin during January to March shows a positive anomaly, but from April to June it shows a negative anomaly with peak value in the month of June. This pressure deficient brings the south west monsoon current over Cochin. Hence the intra seasonal studies surface weather parameters would help in predicting the onset of monsoon over Kerala (normal onset date is June 1), the gate way of Indian summer monsoon. During the monsoon the pressure anomaly changes from $-2 \mathrm{hPa}$ (June) to $+1 \mathrm{hPa}$ (September). This pressure deficit during monsoon season shows the strength of monsoon circulation, ISV of monsoon current and the associated rainfall pattern over the Indian subcontinent. The surface pressure anomaly during monsoon clearly shows the intra-seasonal variability (ISV), which is connected to the more rainy days (active cycles) and less rainy days (break cycles) of Indian summer monsoon season and associated amount of rainfall variability. There are studies available for defining the active and break cycles of Indian summer monsoon, which is of prime importance and concern in the short term prediction of monsoon rainfall [31].

\subsection{Intra-Seasonal Variability}

The ISV of the tropical TCO are large ( $\pm 10 \mathrm{DU})$ and comparable to the total TCO variations in annual and interannual time scales associated with the annual cycle, quasi-biennial oscillation, El Niño-Southern Oscillation, and solar cycle. Insufficient knowledge in the ISV is a major challenge faced by the scientific community in the short term weather prediction and forecast. Indian economy is based on agriculture and hence the prediction and 
timely forecast is very much essential for the farmers to have safer way of doing agricultural activity, which can reduce the economic loss of the country. The study of ISV is very important in the prediction of active and breaks cycles of Indian summer monsoon which is linked to the extreme weather events. The long durations of active and break days can lead to the weather extremes such as floods and drought events. Hence the accurate short term prediction and forecast of weather systems are prime concern for the country to reduce the economic loss.

In this work we have made an attempt to understand the ISV of TCO, surface temperature and pressure during monsoon season and the results were presented in the Figures 2(a)-(d). Figure 2(a) represents the ISV of Indian summer monsoon rainfall, which is adopted from the research report [32] and Figures 2(b)-(d) represent the ISV in TCO, Surface Temperature and Pressure respectively. The ISV in the weather parameters TCO, surface temperature and pressure is clearly understood from the Figure 2. In the figure $\mathrm{x}$-axis denotes the number of days from 1 June to 30th September 5 (June: 1 - 30, July: 31 - 60, August: 61 - 90, and September: 91 - 122). Figure 2(b) represent the ISV in the TCO during monsoon period, that is daily departure from the monsoonal mean (288.8 DU). The intra seasonal variability in the TCO values is noted and in the month of June-July, there is a negative ozone anomaly noted over this region with very short time scale variations. In many of the days in the beginning of this season, the TCO anomaly deviate -10 DU from the seasonal mean value. But in August, the anomaly varies from -5 DU to $+5 \mathrm{DU}$. A positive TCO anomaly variation is noted during almost all the days in the month of September (see Figure 1(a)) and in the last few days the TCO anomaly crossed +10 DU from the seasonal average. Figure 2(c) and Figure 2(d) shows the ISV in the surface temperature and pressure over Cochin. The ISV in the surface temperate anomaly varies between $-1.5^{\circ} \mathrm{C}$ and $+1.5^{\circ} \mathrm{C}$ from the seasonal average $\left(28.6^{\circ} \mathrm{C}\right.$ ) and the surface pressure varies between $-2.5 \mathrm{hPa}$ and $+2 \mathrm{hPa}$ as respectively (Figure 2(d)). Table 1 shows the statistics of ISV in TCO, surface temperature and pressure over Cochin during summer monsoon 2015. There is no correlation of TCO with surface temperature and a positive correlation of 0.35 is noted with surface pressure.

\subsection{MJO Modulated Intra-Seasonal Variability (MJO-ISV)}

The MJO consists of two phases, one is the enhanced phase and the other is the suppressed phase. These two phases produce opposite changes in clouds, rainfall, surface pressure, temperature, and even in the atmospheric composition [16]. The persistence of 40 - 50 day oscillations in stratospheric ozone and temperature was noted in earlier studies [33]. There is also evident that the MJO propagates even higher into the ionosphere [34]. The characteristics of intraseasonal variability are mainly determined by the low and high frequency Intra-seasonal oscillations (ISOs) present during the season. The dynamics and chemistry of the tropical atmosphere is mainly modulated by the ISOs. Hence an understanding of the low and high frequency of ISOs during the season gives a better picture of intra-seasonal variability. The ISOs with different periodicities in the season which modulate the weather and climate over a region implies that ISV is a collective action of ISOs. In order to study the ISV in TCO, surface temperature and pressure over Cochin during the monsoon period, we used Discrete Mayer's Wavelet, techniques which decomposes all possible and significant ISOs present in the above parameters. Hence ISV can be considered as the sum and collective actions of different modes of ISOs present in the particular season. For the wavelet analysis daily values of TCO, surface Temperature and pressure from 29th May to 3rd October 2015 (128 data points) were used and the significant ISOs are shown in Figure 3 to Figure 5 respectively. The x-axis represents the days and y-axis represents the wavelet coefficients for the different modes of ISOs.

Figure 3(a) represents the TCO in Dobson Unit and Figures 3(b)-(f) shows the different possible low and high frequency ISOs during summer monsoon period. The prominent modes of ISOs are MJO mode (30 - 60 days), quasi triweekly mode (18 - 22 days) and quasi bi-weekly (10 - 16 days) mode and weekly mode (6 - 8 days). The other modes with lower periodicities are insignificant in contributing to the ISV. The dominant mode of ISO present in the TCO ISV is MJO mode having 2.5 waves with a periodicity of approximately 48 days during the monsoon season (Figure 3(b)). The phases of MJO modulate the ISV of TCO during the period. It can be seen from the figure that during the positive and negative phases of MJO a positive and negative anomaly of TCO is observed with minor exceptions (see Figure 2(b)).

The second major ISO is having a periodicity greater than quasi-biweekly oscillations and we call it as triweekly oscillations (18 - 22 days) with almost 6 waves during the season (Figure 3(c)). The positive and negative phases of this triweekly ISO contribute to the ISV with a positive TCO anomaly during positive phase and 

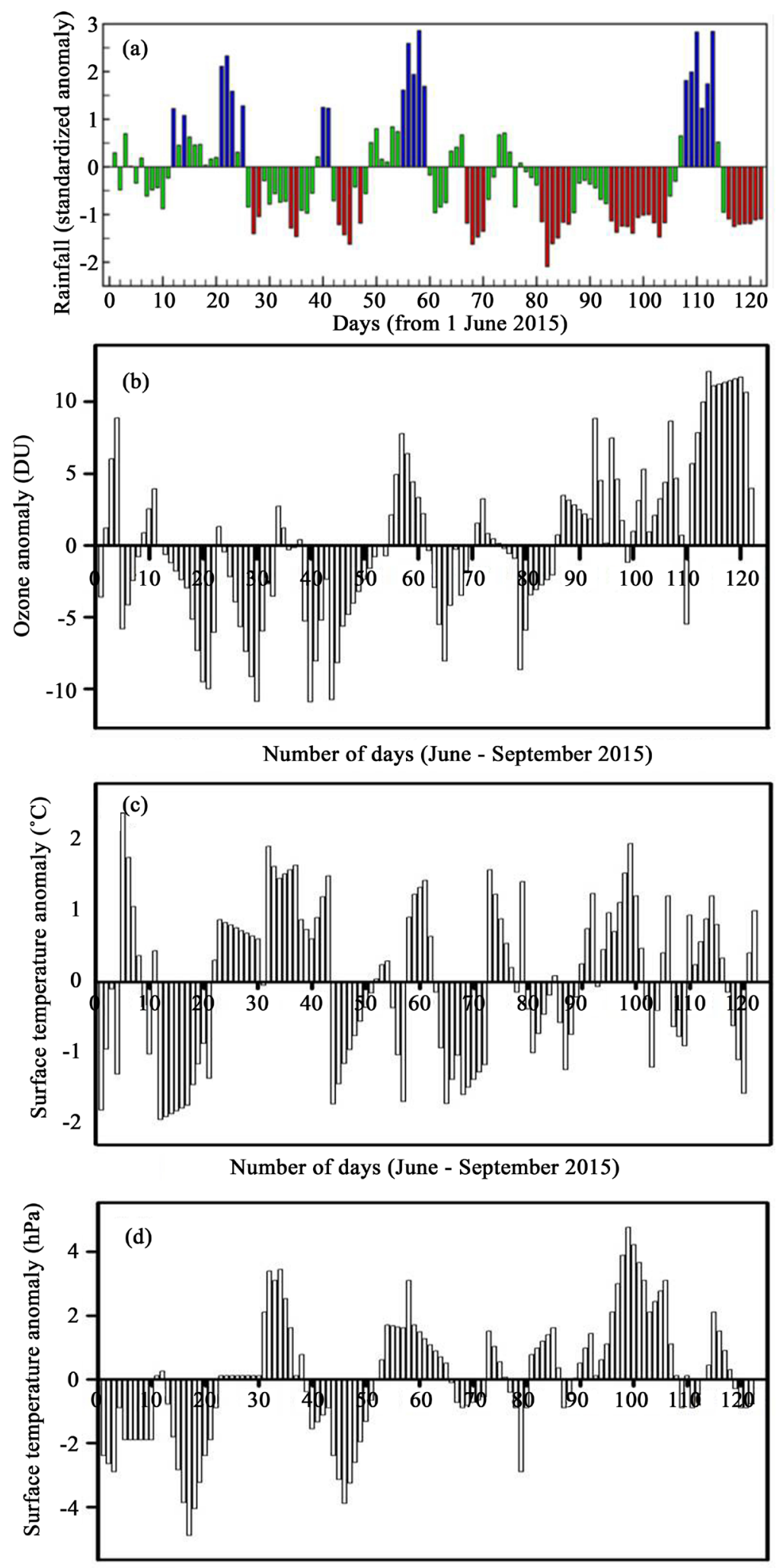

Number of days (June - September 2015)

Figure 2. (a) Represent the Indian summer monsoon rainfall (standard anomaly) for 01 June-30 September, 2015 (Courtesy: Milind Mujumdar, C. Gnanaseelan and Rajeevan [32], http://www/tropmet.res.in; (b)-(d) shows the column ozone, surface temperature and pressure anomalies for the period 01 June-30 September, 2015. 
Table 1. Statistics of TCO, surface temperate and pressure for monsoon period (01 June-30th September 2015).

\begin{tabular}{ccccccc}
\hline Weather parameters & Max. value & Min. value & Seasonal range & Mean & Variance & Std. deviation \\
\hline Total column ozone & $300.8 \mathrm{DU}$ & $277.8 \mathrm{DU}$ & $23 \mathrm{DU}$ & $288.7 \mathrm{DU}$ & 29.3 & 5.1 \\
Surface temperature & $31.6^{\circ} \mathrm{C}$ & $26.7^{\circ} \mathrm{C}$ & $4.9^{\circ} \mathrm{C}$ & $28.6^{\circ} \mathrm{C}$ & 1.2 & 1.08 \\
Surface pressure & $1013.7 \mathrm{hPa}$ & $1004.0 \mathrm{hPa}$ & $9 \mathrm{hPa}$ & $1008.0 \mathrm{hPa}$ & 3.54 & 1.8 \\
\hline
\end{tabular}

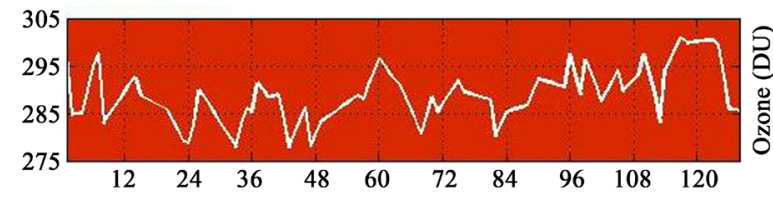

(a)

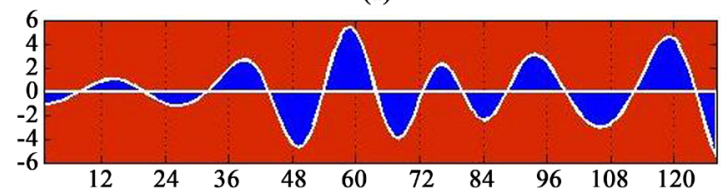

(c)

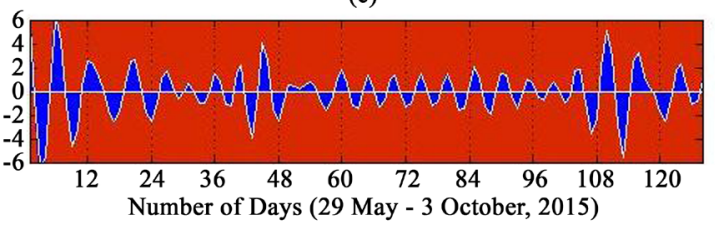

(e)

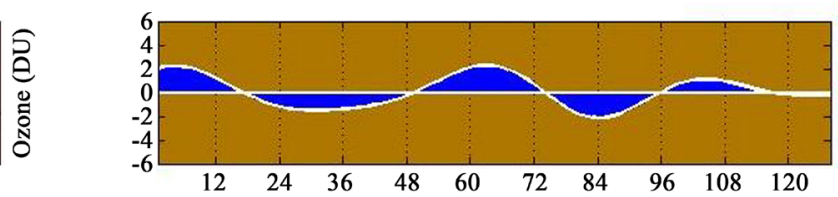

(b)

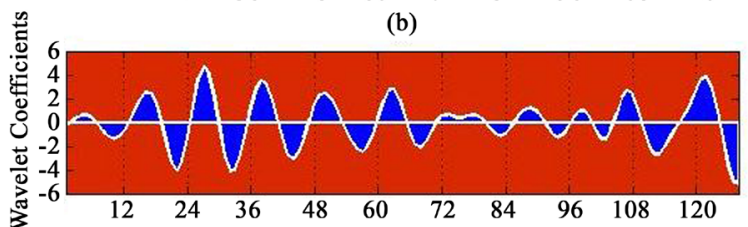

(d)

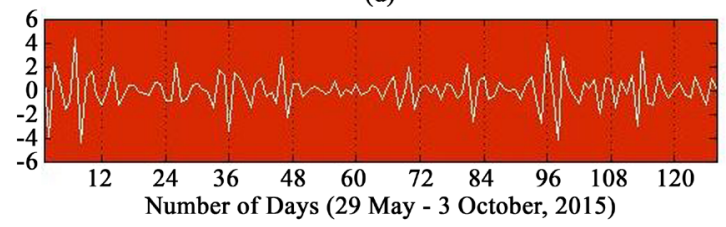

(f)

Figure 3. (a) Total column ozone in DU, (b) MJO mode, (c) quasi triweekly mode, (d) quasi biweekly mode and ((e), (f)) least significant modes and perturbations of ISOs) in the column ozone measured over cochin during the period 29th May03rd October 2015.

negative TCO anomaly during negative phases (see Figure 2(b)). Figure 3(d) represent the ISO mode with 10 16 days periodicity called quasi biweekly oscillations. This mode also contributes to the ISV of TCO. The amplitude of tri-weekly and quasi bi-weekly ISOs are not symmetric. Some waves are more amplified at certain days during the period of study which can determine the amount of ISV variability of ozone (Figure 3(c) and Figure 3(d)). It is also observed that if the amplitude is high for particular wave at particular time of an ISO, corresponding increase (positive phase) and decrease (negative phase) of TCO anomalies are noted during that time with minor exceptions. Figures 3(d)-(f) contribute least to the ISV and it can be considered as simple perturbations or noise. In the ISV of TCO, there are three (MJO, triweekly and biweekly ISOs) modes really contributing to the intraseasonal variability (ISV) of TCO during the monsoon period.

Figure 4(a) represent the surface temperature $\left({ }^{\circ} \mathrm{C}\right.$ ) measured over Cochin and Figures 4(b)-(f) shows the different modes of ISOs present in the surface temperature. Figure 4(b), represent the dominant ISO mode in the temperature ISV. This mode also comes under the MJO periodicity (26 - 36 days). This periodicity is less than the MJO periodicity observed in the TCO. Here total three waves observed but the amplitude of oscillations are not symmetric and the amplitude varies with different period of time during the season.

The phases of MJO modulates the surface temperature over Cochin during monsoon season with +ve phase showing a positive surface temperature anomalies and negative phase with negative temperature anomalies (Figure 4(b) and Figure 3(c)). The two (MJO, and quasi-biweekly modes) ISO periodicities are significant and no tri-weekly modes were present in the surface temperature ISV. The other modes of ISO shown in Figures 4(d)-(f) do not contribute much to the ISV of temperature. In the studies of intra-seasonal oscillations of Indian summer monsoon rainfall, these two modes were already reported [12] [35].

Figure 5(a) represent the variation of surface pressure during the monsoon period and Figures 5(b)-(f), represent the different ISO modes present in the surface pressure. These ISOs modulate the pressure anomalies over the region. Figure 5(b) represents the negative and positive phases of ISOs which correlate with negative and positive pressure anomalies (see Figure 2(d)). The two prominent modes of ISOs in surface pressure are MJO mode (30 - 36 days) and quasi biweekly modes (10 - 16 days). The ISO modes keep an out of phase 

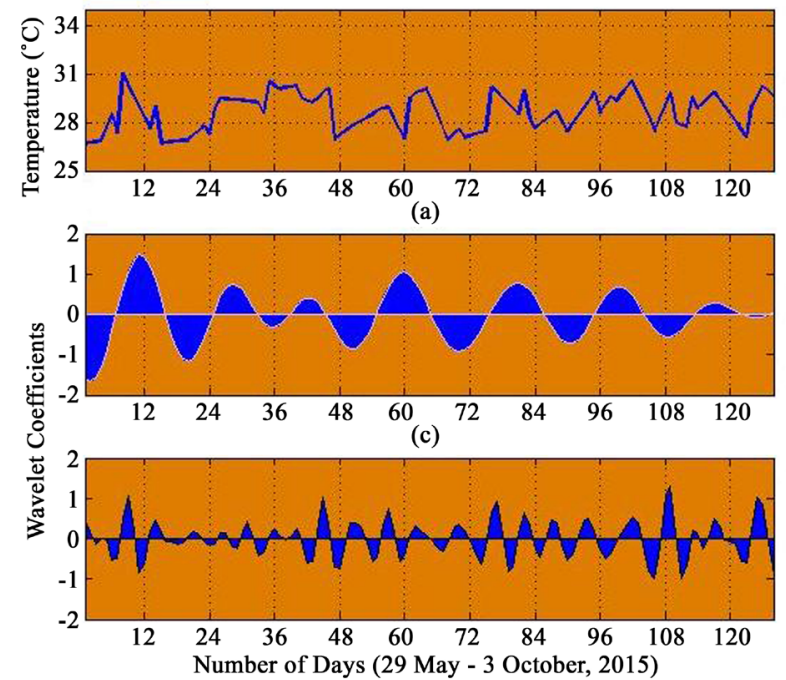

(e)
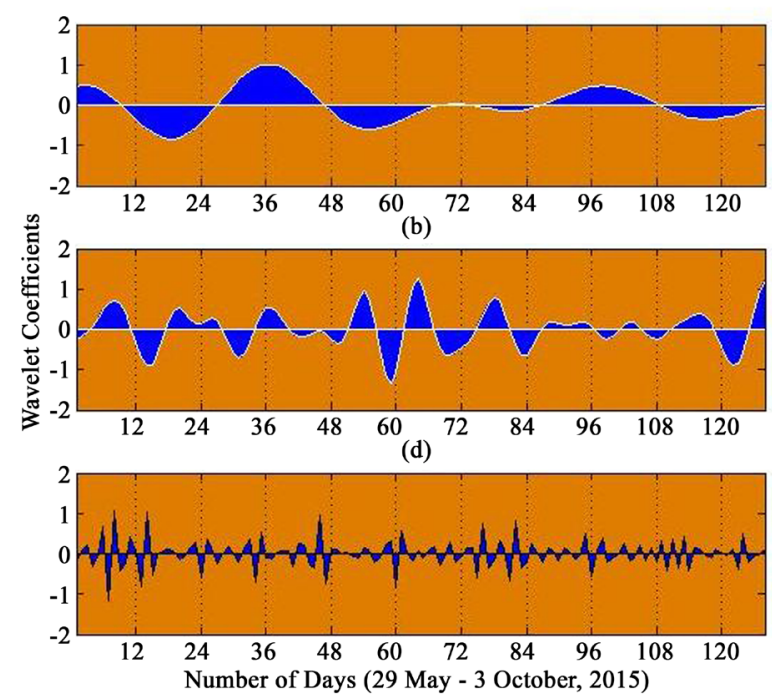

(f)

Figure 4. (a) Surface temperature $\left({ }^{\circ} \mathrm{C}\right)$; (b) MJO mode, (c) quasi biweekly mode and (d)-(f) least significant modes and perturbations of ISOs in the surface temperature measured over cochin during the period 29th May-03rd October 2015.

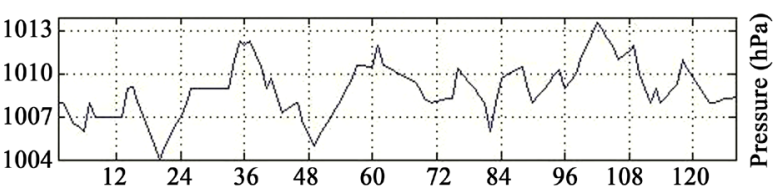

(a)

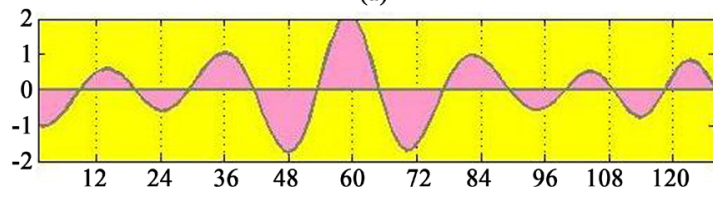

(c)

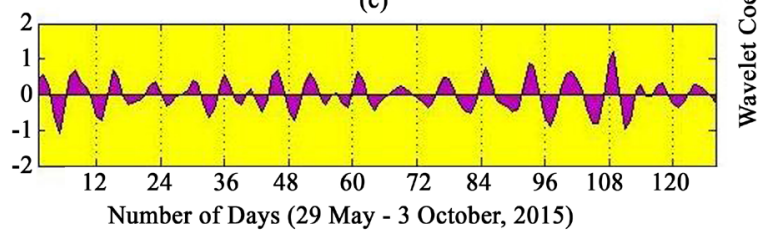

(e)

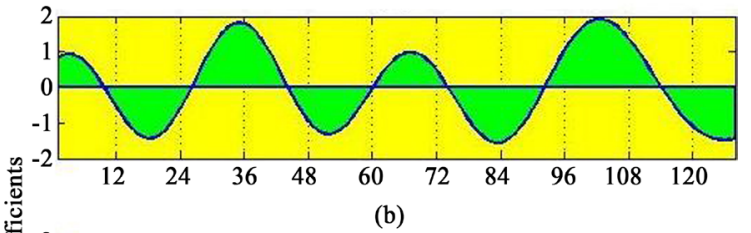

(b)

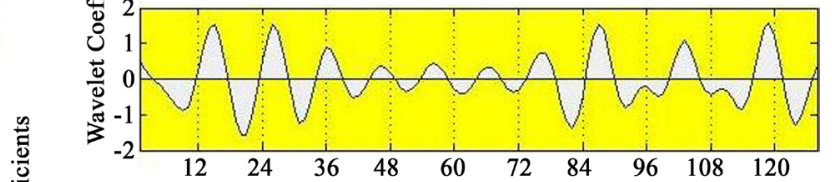

(d)

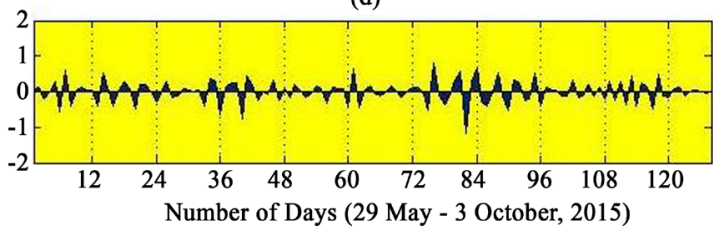

(f)

Figure 5. (a) Surface pressure (hPa); (b) MJO mode; (c) quasi biweekly mode and (d)-(f) least significant modes and perturbations of ISOs in the surface pressure measured over cochin during the period 29th May-03rd October 2015.

relation with Indian summer rainfall during this season (Figure 2(a)). The positive phase of the ISO fall in the break cycles of the Indian summer monsoon rainfall and opposite is true for the active cycles. Thus more case studies are needed to understand the intraseasonal oscillation for the proper predictions of ISV, which in turn affect forecast of extreme weather events. Hence more case studies are required for the better conclusion.

\section{Summary and Conclusion}

In the present study, seasonal and intra-seasonal variations of column ozone, surface temperature and pressure were examined using daily measurements taken using the Microtops II Ozonometer over Cochin during the year 2015. The seasonal analysis of TCO shows an annual mean 279.7 DU with a maximum recorded in the month of September and a minim recorded in winter months. Annual range of variation of TCO is about 30 DU for the year 2015. Surface pressure over Cochin shows a negative anomaly for the April-May period which is an indication of onset of southwest monsoon circulation over Cochin. The annual range of surface pressure oscillations is 
about $4 \mathrm{hPa}$ from the annual mean $(1009.5 \mathrm{hPa})$ with maximum surface pressure in the month of December $(1011.6 \mathrm{hPa})$ and minimum in the month of June $(1007.3 \mathrm{hPa})$. The annual average of surface temperature is $28.6^{\circ} \mathrm{C}$ with surface temperature showing $1^{\circ} \mathrm{C}$ departure from the maximum and minimum for the year 2015 . Considering the importance of the Cochin and its tropical monsoon climate, intra-seasonal studies were focused on the low and high frequency ISOs present in the parameters. From the previous studies it is proved that tropical monsoon regions are undergoing many intra-seasonal oscillations (ISOs) with different time scales, which in turn alter the total intra-seasonal variability leading to the inter-annual variability. This study gives more insight into the ISOs present in the ISV, which in turn help the prediction of extreme weather events such as flood and drought due to the active and break cycles of Indian summer monsoon [12]. From the decompositions of intraseasonal variability, we could identify three major ISOs in the total column ozone (MJO: 30 - 60 days periodicity, quasi triweekly: 18 - 22 days periodicity, quasi biweekly: 10 - 16 days periodicity). The ISO phases are in phase with the variations of TCO, surface and temperature. The positive and negative anomalies of these parameters are in phase with the different modes of ISOs contributing to the total intra-seasonal variability. The MJO and quasi biweekly modes in the surface pressure are out of phase relation with the Indian summer rainfall. In majority of the cases the active and break cycles of Indian summer monsoon fall in the negative and positive phases of the significant ISOs present in the surface pressure. The present study is very much relevant in the context of increased weather events and climate change. Hence we do require more studies of this kind for the proper predictions of weather and climate. For the last few years frequent sunburn cases were reported from Cochin due to exposure towards harmful UV radiation, which shows the thinning of ozone layer over Cochin.

\section{Acknowledgements}

Author is thankful to Indian Space Research Organization-Respond Project and Science and Engineering Research Board (SERB), Department of Science and Technology (DST) for the financial support to carry out this work and also acknowledges Ms. Karthika G and Asifsha T.M. and Ms. Saritha AC for the preparation of Manuscript. Also acknowledge two anonymous reviewers who gave the critical review comments and suggestions for the improvement of this article.

\section{References}

[1] Krishnamurti, T.N. and Ardanuy, P. (1980) The 10 to 20 Day Westward Propagating Mode and "Breaks in the Monsoon”. Tellus, 32, 15-26. http://dx.doi.org/10.1111/j.2153-3490.1980.tb01717.x

[2] Krishnamurti, T.N. and Bhalme, H.N. (1976) Oscillations of a Monsoon System. Part 1. Observational Aspects. Journal of the Atmospheric Sciences, 33, 1937-1954. http://dx.doi.org/10.1175/1520-0469(1976)033<1937:OOAMSP>2.0.CO;2

[3] Yasunari, T. (1979) Cloudiness Fluctuations Associated with the Northern Hemisphere Summer Monsoon. Journal of the Meteorological Society of Japan, 57, 227-242.

[4] Yasunari, T. (1980) A Quasi-Stationary Appearance of the 30 - 40 Day Period in the Cloudiness Fluctuations during the Summer Monsoon over India. Journal of the Meteorological Society of Japan, 58, 225-229.

[5] Lau, K.M. and Chan, P.H. (1986) Aspects of the 40 - 50 Day Oscillation during the Northern Summer as Inferred from Ongoing Long Wave Radiation. Monthly Weather Review, 114, 1354-1367. http://dx.doi.org/10.1175/1520-0493(1986)114<1354:AOTDOD>2.0.CO;2

[6] Ferranti, L., Slingo, J.M., Palmer, T.N. and Hoskins, B. (1997) Relations between Intraseasonal and Interannual Monsoon Variability as Diagnosed from AMIP Integrations. Quarterly Journal of The Royal Meteorological Society, 123, 1323-1357. http://dx.doi.org/10.1002/qj.49712354110

[7] Goswami, B.N., Sengupta, D. and Suresh Kumar, G. (1998) Intraseaonal Oscillations and Interannual Variability of Surface Winds over the Indian Monsoon Region. Proceedings of the Indian Academy of Sciences (Earth and Planetary Sciences), 107, 45-64.

[8] Goswami, B.N. and Ajayamohan, R.S. (2001) Intraseasonal Oscillations and Interannual Variability of the Indian Summer Monsoon. Journal of Climate, 14, 1180-1198. http://dx.doi.org/10.1175/1520-0442(2001)014<1180:IOAIVO>2.0.CO;2

[9] Goswami, B.N. (2005) Intraseasonal Variability (ISV) of South Asian Summer Monsoon. In: Lau, K. and Waliser, D., Eds., Intraseasonal Variability of the Atmosphere-Ocean Climate System, Springer-Praxis, Chichester. http://dx.doi.org/10.1007/3-540-27250-X 2

[10] Madden, R.A. and Julian, P.R. (1972) Description of Global-Scale Circulation Cells in the Tropics with a 40 - 50 Day 
Period. Journal of the Atmospheric Sciences, 29, 1109-1123.

http://dx.doi.org/10.1175/1520-0469(1972)029<1109:DOGSCC>2.0.CO;2

[11] Wang, B. and Rui, H. (1990) Synoptic Climatology of Transient Tropical Intraseasonal Convective Anomalies. Meteorology and Atmospheric Physics, 44, 43-61. http://dx.doi.org/10.1007/BF01026810

[12] Rajeevan, M., Gadgil, S. and Bhate, J. (2010) Active and Break Spells of the Indian Summer Monsoon. Journal of Earth System Science, 119, 229-247. http://dx.doi.org/10.1007/s12040-010-0019-4

[13] Sulochana, G. and Joseph, P.V. (2003) On Breaks of the Indian Monsoon. Proceedings of the Indian Academy of Sciences (Earth and Planetary Sciences), 112, 529-558.

[14] Madden, R. and Julian, P. (1971) Detection of a 40 - 50 Day Oscillation in the Zonal Wind in the Tropical Pacific. Journal of the Atmospheric Sciences, 28, 702-708. http://dx.doi.org/10.1175/1520-0469(1971)028<0702:DOADOI >2.0.CO;2

[15] Madden, R.A. and Julian, P.R. (1972) Description of Global-Scale Circulation Cells in the Tropics with a 40 - 50 Day Period. Journal of the Atmospheric Sciences, 29, 1109-1123. http://dx.doi.org/10.1175/1520-0469(1972)029<1109:DOGSCC>2.0.CO;2

[16] Zhang, C. (2005) Madden-Julian Oscillation. Reviews of Geophysics, 43, 1-36. http://dx.doi.org/10.1190/1.1988182

[17] Wheeler, M.C. and Hendon, H.H. (2004) An All-Season Realtime Multi-Variate MJO Index: Development of an Index for Monitoring and Prediction. Monthly Weather Review, 132, 1917-1932. http://dx.doi.org/10.1175/1520-0493(2004)132<1917:AARMMI>2.0.CO;2

[18] Tian, B.J., Yung, Y.L., Waliser, D.E., Tyranowski, T., Kuai, L., Fetzer, E.J. and Irion, F.W. (2007) Intraseasonal Variations of the Tropical Total Ozone and Their Connection to the Madden-Julian Oscillation. Geophysical Research Letters, 34, L08704. http://dx.doi.org/10.1029/2007GL029451

[19] Pai, D.S., Bhate, J., Sreejith, O.P. and Hatwar, H.R. (2009) Impact of MJO on the Intraseasonal Variation of Summer Monsoon Rainfall over India. Climate Dynamics.

[20] Jones, C. and Carvalho, L. (2002) Active and Break Phases in the South American Monsoon System. Journal of Climate, 15, 905-914. http://dx.doi.org/10.1175/1520-0442(2002)015<0905:AABPIT>2.0.CO;2

[21] Lavender, S. and Matthews, A. (2009) Response of the West African Monsoon to the Madden-Julian Oscillation. Journal of Climate, 22, 4097-4116. http://dx.doi.org/10.1175/2009JCLI2773.1

[22] Maloney, E. and Hartmann, D. (2000) Modulation of Hurricane Activity in the Gulf of Mexico by the Madden-Julian Oscillation. Science, 287, 2002-2004. http://dx.doi.org/10.1126/science.287.5460.2002

[23] Madden, R.A. and Julian, P.R. (1994) Observations of the 40-50-Day Tropical Oscillations-A Review. Monthly Weather Review, 122, 814-837. http://dx.doi.org/10.1175/1520-0493(1994)122<0814:OOTDTO>2.0.CO;2

[24] Maloney, E.D. and Hartmann, D.L. (2000) Modulation of Hurricane Activity in the Gulf of Mexico by the Madden-Julian Oscillation. Science, 287, 2002-2004. http://dx.doi.org/10.1126/science.287.5460.2002

[25] Maloney, E.D. and Hartmann, D.L. (2000) Modulation of Eastern North Pacific Hurricanes by the Madden-Julian Oscillation. Journal of Climate, 13, 1451-1460. http://dx.doi.org/10.1175/1520-0442(2000)013<1451:MOENPH>2.0.CO;2

[26] Fioletov, V.E. (2008) Ozone Climatology, Trends, and Substances That Control Ozone. Atmosphere-Ocean, 46, 39-67. http://dx.doi.org/10.3137/ao.460103

[27] Morys, M., Mims III, F.M., Hagerup, S., Anderson, S.E., Baker, A., Kia, J. and Walkup, T. (2001) Design, Calibration, and Performance of MICROTOPS II Handheld Ozone Monitor and Sun Photometer. Journal of Geophysical Research, 106, 14573-14582. http://dx.doi.org/10.1029/2001JD900103

[28] Gomez-Amo, J.L., Estelles, V., di Sarra, A., Pedrós, R., Utrillas, M.P., Martínez-Lozano, J.A., et al. (2012) Operational Considerations to Improve Total Ozone Measurements with a Microtops II Ozone Monitor. Atmospheric Measurement Techniques, 5, 759-769. http://dx.doi.org/10.5194/amt-5-759-2012

[29] Abry, P. (1997) Ondelettes et turbulence. Multirésolutions, algorithmes de décomposition, invariance d'échelles, Diderot Editeur, Paris, 268.

[30] Madhu, V. (2014) Spatial and Temporal Variability of Total Column Ozone over the Indian Subcontinent: A Study Based on Nimbus-7 TOMS Satellite. Atmospheric and Climate Sciences, 4, 884-898. http://dx.doi.org/10.4236/acs.2014.45078

[31] Rajeevan, M., Unnikrishnan, C.K., Bhate, J., Niranjan Kumar, K. and Sreekala, P.P. (2012) Northeast Monsoon over India: Variability and Prediction. Meteorological Applications, 19, 226-236. http://dx.doi.org/10.1002/met.1322

[32] Mujumdar, M., Gnanaseelan, C. and Rajeevan, M. (2015) A Research Report on the 2015 Southwest Monsoon. ESSO/IITM/SERP/SR/02(2015)/185. http://www/tropmet.res.in 
[33] Chandra, S. (1986) The Solar and Dynamically Induced Oscillations in the Stratosphere. Journal of Geophysical Research, 91, 2719-2734. http://dx.doi.org/10.1029/JD091iD02p02719

[34] Stanford, J.L. and Saksena, R.C. (1989) Oscillations in D-Region Absorption at Periods of One to Two Months. Journal of Atmospheric and Terrestrial Physics, 51, 955-981. http://dx.doi.org/10.1016/0021-9169(89)90012-3

[35] Charlotte, B.V., Simon, E.K., George, G., Yesodharan, S. and Ruchith, R.D. (2012) Intra-Seasonal Oscillation of North East Monsoon over Southern Peninsular India-An Investigation. International Journal of Scientific and Research Publications, 2. http://www.ijsrp.org/research-paper-0812/ijsrp-p0829.pdf

[36] Madhu, V. and Gangadharan, K. (2016) Temporal Distribution of Total Column Ozone over Cochin—A Study Based on in Situ Measurements and ECMWF Reanalysis. Open Journal of Marine Science, 6, 200-209. http://dx.doi.org/10.4236/ojms.2016.62016 